\title{
Stability and adaptability of grain sorghum hybrids in the off-season
}

\author{
J.E. Almeida Filho ${ }^{1}$, F.D. Tardin ${ }^{2}$, R.F. Daher ${ }^{1}$, T.C. Barbé1, C.M. Paula ${ }^{3}$, \\ M.J. Cardoso ${ }^{4}$ and V.P.C. Godinho \\ ${ }^{1}$ Laboratório de Engenharia Agrícola, \\ Centro de Ciências e Tecnologias Agropecuárias, \\ Universidade Estadual do Norte Fluminense Darcy Ribeiro, \\ Campos dos Goytacazes, RJ, Brasil \\ ${ }^{2}$ Núcleo de Recursos Genéticos e Obtenção de Cultivares, \\ Embrapa Milho e Sorgo, Sete Lagoas, MG, Brasil \\ ${ }^{3}$ Departamento Comercial, Cereal Ouro, Rio Verde, GO, Brasil \\ ${ }^{4}$ Setor de Produção Vegetal, Grupo de Pesquisa e Desenvolvimento, \\ Embrapa Meio Norte, Teresina, PI, Brasil \\ ${ }^{5}$ Núcleo de Produção Vegetal, Embrapa Rondônia, Vilhena, RO, Brasil \\ Corresponding author: J.E. Almeida Filho \\ E-mail: janeo.eustaquio@ymail.com
}

Genet. Mol. Res. 13 (3): 7626-7635 (2014)

Received December 12, 2012

Accepted April 25, 2013

Published March 24, 2014

DOI http://dx.doi.org/10.4238/2014.March.24.24

ABSTRACT. We analyzed productivity data obtained from experiments
on grain sorghum conducted in 7 locations of its cultivation in Brazil. A
total of 25 hybrids were analyzed, of which 22 were pre-commercial and
3 were cultivars. The Wricke and Purchase et al. methods were highly
consistent in identifying individuals with low contributions to genotype x
environment interactions. The Lin and Binns method proved to be easily
applicable and interpretable but it was not efficient in detecting individuals
with specific adaptations. An additive main effect and multiplicative
interaction (AMMI) model indicated the suitability of cultivar $1 \mathrm{G} 282$ for
the cities of Guaíra, Sete Lagoas, and Vilhena, and hybrids 0307087 and
0307091 for the southeast of Goiás. The associations of the Eberhart and
Russell method with AMMI indicated that $0307071,0307131,0307511$, 
and 0307651 showed adaptability to favorable environments. Hybrid 0009061 stood out as the most adaptable and stable cultivar.

Key words: Genotype x environment interaction; Sorghum bicolor; Sorghum breeding

\section{INTRODUCTION}

The culture of grain sorghum is an important cultivation alternative for the second harvest, and is also known as the off-season crop. Considering its economic importance, public and private ventures for the administration of breeding programs of this culture are necessary, since they are responsible for annually testing several promising genotypes in many environments for their cultivation.

Grain sorghum cultivation occurs across various environments characterized by highly diversified soil and climate conditions. When promising materials are evaluated for recommendation, a common problem identified is that the high productivity observed in some genotypes at a certain location or in a certain year does not remain if the environment changes. Such instability creates difficulty for recommending cultivars.

A different response of a genotype under different environments is known as a genotype by environment $(\mathrm{G} \times \mathrm{E}$ ) interaction. The complications resulting from $\mathrm{G} \times \mathrm{E}$ interactions can be best avoided by the identification of stable genotypes that are adapted to cultivation conditions (Cruz and Regazzi, 1997).

According to Mariotti et al. (1976), stability is associated with the predictability or performance of genotypes in the face of environmental variation and by their adaptive potential to advantageously assimilate environmental stimuli.

According to Cruz and Regazzi (1997), several methodologies have been proposed to study stability and adaptability. These methods are all generally based on identifying significant interactions, but differ based on the particular stability concepts adopted and some of the statistical principles employed; some methods are conflicting, while others are complementary.

Adaptability can be studied by determining the contribution of the genotype to the $\mathrm{G}$ $\mathrm{x}$ E interaction (Wricke, 1965). This contribution can also be measured by a principal component analysis, using an additive main effect and multiplicative interaction (AMMI; Zobel et al., 1988) model, or the index described in Purchase et al. (2000).

Some methods consider the concepts of stability and adaptability simultaneously, such as the regression model of Eberhart and Russell (1966), which measures stability by model fitting and adaptability by the regression coefficient. In addition, Lin and Binns (1988) suggested a non-parametric performance index, which aggregates stability and adaptability to a single index; this method is widely used because of its ease of interpretation.

In all studies of stability and adaptability, it is important to incorporate several methods simultaneously, and thus capture their information in an integrated manner. Therefore, the objective of this study was to analyze the stability and adaptability of simple hybrids of grain sorghum that were evaluated in several Brazilian environments where this culture is produced.

\section{MATERIAL AND METHODS}

We here evaluated data collected from experiments conducted by the Embrapa Milho 
e Sorgo across several locations in Brazil (Table 1). In all cases, grain sorghum was planted between the end of February and the beginning of March 2011, which is characteristic of the off-season in all locations assessed, except for Teresina.

Table 1. Geographical description of the locations assessed.

\begin{tabular}{lccc}
\hline Locations (City-State) & Altitude $(\mathrm{m})^{1}$ & Latitude & Longitude \\
\hline Água Comprida-MG & 535 & $-20^{\circ} 03^{\prime}$ & $-48^{\circ} 06^{\prime}$ \\
Guaíra-SP & 507 & $-20^{\circ} 19^{\prime}$ & $-48^{\circ} 19^{\prime}$ \\
Montividiu-GO & 833 & $-17^{\circ} 26^{\prime}$ & $-51^{\circ} 10^{\prime}$ \\
Rio Verde-GO & 754 & $-17^{\circ} 47^{\prime}$ & $-50^{\circ} 55^{\prime}$ \\
Sete Lagoas-MG & 773 & $-19^{\circ} 28^{\prime}$ & $-44^{\circ} 15^{\prime}$ \\
Teresina-PI & 81 & $-5^{\circ} 05^{\prime}$ & $-42^{\circ} 48^{\prime}$ \\
Vilhena-RO & 577 & $-12^{\circ} 44^{\prime}$ & $-60^{\circ} 08^{\prime}$ \\
\hline
\end{tabular}

${ }^{1}$ Data obtained from satellite monitoring by the Google Earth 6 software.

A randomized block design was adopted, with 3 replications and 25 hybrids. Twentytwo of the hybrids were pre-commercial simple hybrids obtained from the Núcleo de Recursos Genéticos e Desenvolvimento de Cultivares (Center for Genetic Resources and Development of Cultivars) of Embrapa Milho e Sorgo, and the other 3 were the commercial cultivars 1G282, BRS 308, and BRS 330.

Plots were built with 4 rows, spaced $0.5 \mathrm{~m}$ from one another, with an average stand of 200,000 plants/ha. Each of the rows was $5 \mathrm{~m}$ in length, using only the 2 central rows as the useful area of the plot. Grains were collected from the plot and were subsequently measured and corrected to a moisture level of $13 \%$.

In the experiments conducted in Água Comprida, Rio Verde, and Montividiu, plots were implanted after commercial soy cultivation. These soil conditions were particularly favorable because soy associates with bacteria of the genus Bradyrhizobium, which captures the atmospheric nitrogen and makes it available for the plants. Irrigation was not used in any of the experiments.

The statistical evaluation of the results was initially performed with analysis of variance for each experiment independently, adopting the model:

$$
Y_{i j}=\mu+G_{i}+B_{j}+\varepsilon_{i j}
$$

(Equation 1)

where $Y_{\mathrm{ij}}$ is the grain yield $(\mathrm{kg} / \mathrm{ha})$ of the plot that received genotype $\mathrm{i}$, allocated in block $\mathrm{j} ; \mu$ is the overall constant; $G_{\mathrm{i}}$ is the fixed effect of the $\mathrm{i}^{\text {th }}$ genotype; $B_{\mathrm{j}}$ is the random effect of the $\mathrm{j}^{\text {th }}$ block, and $\mathrm{B}_{\mathrm{j}} \sim \mathrm{NID}\left(0, \mathrm{~s}_{\mathrm{B}}^{2}\right) ; \varepsilon_{\mathrm{ij}}$ is the random effect of the experimental error observed in plot ij, and $\varepsilon_{\mathrm{ij}} \sim \mathrm{N} I D\left(0, \sigma^{2}\right)$.

After the individual analysis of variance, we analyzed the feasibility of performing a combined variance analysis, according to the reasoning proposed by Pimentel-Gomes (2009), who suggested that combined variance analysis should only be performed if the relationship between the residual variances of the experiments is lower than 7 .

For the analysis of variance considering all experiments, the following model was adopted:

$$
Y_{i j k}=\mu+B_{k}\left(E_{j}\right)+G_{i}+E_{j}+G_{i} E_{j}+\varepsilon_{i j k} \quad \text { (Equation 2) }
$$


where $B_{\mathrm{k}}\left(E_{\mathrm{j}}\right)$ is the random effect of block k on environment $\mathrm{j}$, and $\mathrm{B}_{\mathrm{k}}\left(\mathrm{E}_{\mathrm{j}}\right) \sim \mathrm{NID}\left(0, \sigma_{\mathrm{B}(\mathrm{E})}^{2}\right) ; E_{\mathrm{j}}$ is the random effect of the $\mathrm{j}^{\text {th }}$ environment, and $\mathrm{E}_{\mathrm{j}} \sim \mathrm{NID}\left(0, \sigma_{\mathrm{E}}^{2}\right) ; G_{\mathrm{i}} E_{\mathrm{j}}$ is the random effect of the interaction between genotype $i$ and environment $j$, and $\mathrm{G}_{\mathrm{i}} \mathrm{E}_{\mathrm{j}} \sim \mathrm{NID}\left(0, \sigma_{\mathrm{GE}}^{2}\right)$; and the other terms are the same as defined above.

Subsequently, 5 different methodologies to determine stability and adaptability were compared: Wricke (1965), Eberhart and Russell (1966), Lin and Binns (1988), AMMI (Zobel et al, 1988), and Purchase et al. (2000).

The Wricke (1965) method estimates parameter $\omega$, also known as the ecovalence, which measures stability by the contribution of the genotype for the sum of squares of the deviations due to the $\mathrm{G} \times \mathrm{E}$ interaction. The estimator of this parameter is given by:

$$
\widehat{\omega}_{i}=r \Sigma_{j}\left(\bar{Y}_{i j}-\bar{Y}_{i .}-\bar{Y}_{i j}+\bar{Y}_{. .}\right)^{2}
$$

where $r$ is the number of replications and $\bar{Y}_{\mathrm{ij}}, \bar{Y}_{i .}, \bar{Y}_{\mathrm{j},}$, and $\bar{Y}$.. are the mean of the plot that received genotype $i$ in environment $j$, the overall mean of genotype $i$, the mean of environment $\mathrm{j}$, and the overall mean, respectively.

The Eberhart and Russell (1966) method analyzes genotypes by the following linear regression model:

$$
\mathrm{Y}_{\mathrm{ij}}=\mu+\beta_{\mathrm{i}} \mathrm{I}_{\mathrm{j}}+\delta_{\mathrm{ij}}+\bar{\varepsilon}_{\mathrm{ij}}
$$

where $\mu$ is the intercept, whose estimate represents the genotype mean; $\beta_{\mathrm{i}}$ is the slope coefficient of the regression model; $I_{\mathrm{j}}$ is the independent variable, which is an environmental index obtained by:

$$
I_{j}=\bar{Y}_{. j}-\bar{Y}_{.}
$$

where $\delta_{\mathrm{ij}}$ is the deviation of the model of genotype $\mathrm{i}$ in environment $\mathrm{j}$; and $\varepsilon_{\mathrm{ij}}$ is the mean experimental error.

This method represents adaptability through the slope coefficient of the regression model, which can be lower, higher, or statistically equal to 1 , indicating adaptability to unfavorable environments, favorable environments, or overall adaptability, respectively. In this method, stability is measured by the fit to the model, i.e., more stable individuals show high $\mathrm{R}^{2}$ values and consequently low deviation variances.

The Lin and Binns (1988) method proposes the utilization of a performance index that considers stability and adaptability simultaneously. This index is obtained by:

$$
P_{i}=\Sigma_{j}\left(\bar{Y}_{i j}-\bar{M}_{j}\right)^{2} /(2 n)
$$

where $\bar{M}_{\mathrm{j}}$ is the highest mean observed in environment $\mathrm{j}$, and $n$ is the number of environments. This index can also be deployed into the following:

$$
P_{i}=\left[n\left(\bar{Y}_{i j}-\bar{M}\right)^{2}+\Sigma_{j}\left(\bar{Y}_{i j}-\bar{Y}_{i .}-\bar{M}_{j}+\bar{M}\right)^{2}\right] /(2 n) \quad \text { (Equation 7) }
$$

where the first term corresponds to the genetic deviation $\left(P_{\mathrm{Gi}}\right)$ and the second term corresponds to the deviation caused by the interaction $\left(P_{\mathrm{GEi}}\right)$. According to these authors, the first part does 
not imply alterations in the classification of the materials; however, the second can be modified. Thus, the ideal genotype is one with a low $P_{i}$ value that is mostly attributed to the genetic deviation (Farias et al., 1997).

The AMMI analysis combines the variance analysis with a principal component analysis. In this approach, the interaction component of the combined variance analysis model is analyzed by multiplicative terms obtained by the decomposition of singular values.

In the present analysis, the interaction component will be deployed into the following:

$$
\left(\Sigma_{\mathrm{k}} \lambda_{\mathrm{k}} \gamma_{\mathrm{ik}} \alpha_{\mathrm{jk}}\right)+\rho_{\mathrm{ij}}
$$

(Equation 8)

where $\lambda_{\mathrm{k}}$ is the $\mathrm{k}^{\text {th }}$ singular vector of the original matrix of interactions $(\mathrm{GxE}) ; \gamma_{\mathrm{ik}}$ is the value associated with the $\mathrm{i}^{\text {th }}$ genotype in the $\mathrm{k}^{\text {th }}$ singular vector column of the $\mathrm{G} \times \mathrm{E}$ matrix; $\alpha_{\mathrm{jk}}$ is the value associated with the $\mathrm{j}^{\text {th }}$ environment of the singular vector row of the G x E matrix; $\rho_{\mathrm{ij}}$ is the noise associated with the term $(\mathrm{ge})_{\mathrm{ij}}$, and is defined as:

$$
\rho_{\mathrm{ij}}=\left(\sum_{\mathrm{k}=\mathrm{n}+1}^{\mathrm{D}} \lambda_{\mathrm{k}} \gamma_{\mathrm{ik}} \alpha_{\mathrm{jk}}\right)
$$

(Equation 9)

where $p$ is the rank of the matrix of interactions. The terms of the matrix of interactions can be obtained by:

$$
(\widehat{\mathrm{ge}})_{\mathrm{ij}}=\overline{\mathrm{Y}}_{\mathrm{ij}}-\overline{\mathrm{Y}}_{\mathrm{i} .}-\overline{\mathrm{Y}}_{\mathrm{j}}+\overline{\mathrm{Y}}_{-}
$$

(Equation 10)

The AMMI analysis measures the contribution of genotypes to the interaction effect. This analysis is usually performed by constructing a biplot graph. According to this model, the lower the scores relative to the number of principal components used, the lower the contribution to the $\mathrm{G} x \mathrm{E}$ interaction.

The Purchase et al. (2000) method proposes an index named the AMMI stability value (ASV), which is based on the Euclidean distance between the scores of principal components 1 and 2 of the interaction matrix (IPCA1 and IPCA2, respectively) obtained by the AMMI2 model with the origin, but with a weighing factor because the first component explains a greater portion of the sum of squares of the $\mathrm{Gx}$ E interaction. This index is obtained as follows:

$$
\mathrm{ASV}_{\mathrm{i}}=\sqrt{\left[\left(\mathrm{SS}(\mathrm{IPCA} 1) / \mathrm{SS}(\mathrm{IPCA} 2)\left(\text { IPCA1 }_{\mathrm{i}} \text { score }\right)\right]^{2}+\left(\text { IPCA2 }_{\mathrm{i}} \text { score }\right)^{2}\right.} \quad \text { (Equation 11) }
$$

where SSIPCA1 and SSIPCA2 are the sum of squares of principal components 1 and 2, respectively.

We utilized the Spearman rank correlation to compare the different methods (Steel and Torrie, 1960). For this analysis, all statistics were classified in descending order (Mekbib, 2003; Silva and Duarte, 2006; Cargnelluti Filho et al., 2007; Mohammadi and Amri, 2008; Scapim et al., 2010; Vilela et al., 2011; Pena et al., 2012).

\section{RESULTS}

The individual variance analysis revealed a significant hybrid effect in Guaíra, Montividiu, Sete Lagoas, Teresina, and Vilhena, whereas the effect of hybrids was not significant in 
Água Comprida and Rio Verde (Table 2). The combined analysis revealed significant effects of hybrid, environment, and the interaction between these 2 factors, demonstrating different responses of the hybrids to environmental variation (Table 3 ).

Table 2. Summary of variance analysis for grain yield in kg/ha in Água Comprida (AC), Guaíra (GUA), Montividiu (MON), Rio Verde (RV), Sete Lagoas (SL), Teresina (TER), and Vilhena (VIL).

\begin{tabular}{|c|c|c|c|c|c|c|c|c|}
\hline \multirow[t]{2}{*}{ Hybrid } & \multicolumn{8}{|c|}{ Location } \\
\hline & $\mathrm{AC}$ & GUA & MON & RV & SL & TER & VIL & Mean \\
\hline 0009061 & 4014.83 & 4298.70 & 3553.13 & 6207.66 & 4722.61 & 6121.16 & 4367.13 & 4755.03 \\
\hline 0144013 & 4179.85 & 3545.29 & 3808.25 & 5679.83 & 4838.23 & 5846.33 & 3735.68 & 4519.06 \\
\hline 0307001 & 3749.66 & 4793.62 & 2795.82 & 5965.37 & 4499.54 & 6232.22 & 2878.93 & 4416.45 \\
\hline 0307047 & 3871.57 & 4362.79 & 3746.48 & 6403.13 & 4076.84 & 6304.68 & 3460.47 & 4603.71 \\
\hline 0307061 & 4271.11 & 4658.15 & 3036.16 & 5744.54 & 4832.06 & 5863.60 & 4118.71 & 4646.33 \\
\hline 0307063 & 4171.95 & 3882.61 & 2959.91 & 5880.17 & 4407.07 & 6561.79 & 3624.58 & 4498.30 \\
\hline 0307071 & 3734.29 & 4292.96 & 3825.44 & 6307.92 & 4145.86 & 7149.56 & 2520.99 & 4568.14 \\
\hline 0307087 & 3710.73 & 3848.66 & 3982.91 & 6717.03 & 3861.10 & 6637.93 & 3494.91 & 4607.61 \\
\hline 0307091 & 3929.81 & 2658.89 & 4070.35 & 6065.08 & 3009.38 & 5183.39 & 2719.09 & 3948.00 \\
\hline 0307095 & 3344.87 & 4079.86 & 2920.06 & 5698.54 & 3204.07 & 5844.80 & 2215.48 & 3901.10 \\
\hline 0307131 & 3689.20 & 2586.90 & 2914.65 & 6014.44 & 3528.57 & 7622.18 & 2508.87 & 4123.54 \\
\hline 0307341 & 3789.73 & 4071.33 & 2905.04 & 6027.37 & 3814.80 & 6689.55 & 3788.74 & 4440.94 \\
\hline 0307343 & 4168.51 & 4439.93 & 2776.73 & 6400.75 & 4163.82 & 5882.02 & 4166.22 & 4571.14 \\
\hline 0307401 & 4023.68 & 3150.88 & 2393.94 & 5633.66 & 2919.78 & 6718.42 & 3477.89 & 4045.46 \\
\hline 0307421 & 3565.75 & 4721.50 & 3157.69 & 5066.58 & 4960.38 & 6170.77 & 4247.98 & 4555.81 \\
\hline 0307509 & 3082.68 & 2902.83 & 3211.57 & 5659.61 & 2864.25 & 6421.76 & 2476.36 & 3802.72 \\
\hline 0307511 & 4104.75 & 3067.82 & 2804.19 & 5919.77 & 3311.36 & 6725.22 & 2645.89 & 4082.71 \\
\hline 0307541 & 3770.84 & 4391.56 & 2579.13 & 6195.92 & 4156.58 & 6049.61 & 4010.28 & 4450.56 \\
\hline 0307561 & 3995.67 & 4469.44 & 3008.56 & 6003.95 & 4139.83 & 6242.81 & 4141.80 & 4571.72 \\
\hline 0307651 & 3406.90 & 3592.79 & 3187.22 & 5943.46 & 3967.70 & 7192.40 & 2899.22 & 4312.81 \\
\hline 0307671 & 3843.91 & 3338.97 & 3786.06 & 5336.16 & 4555.23 & 6514.21 & 3490.78 & 4409.33 \\
\hline 0307689 & 3897.82 & 2982.80 & 3399.12 & 5184.41 & 4216.36 & 6919.81 & 3809.56 & 4344.27 \\
\hline $1 \mathrm{G} 282$ & 3880.31 & 5012.35 & 3753.74 & 5600.24 & 5575.03 & 6553.11 & 4384.84 & 4965.66 \\
\hline BRS 308 & 4410.34 & 5112.08 & 4071.53 & 5652.82 & 4242.48 & 5086.83 & 4858.74 & 4776.40 \\
\hline BRS 330 & 2945.17 & 3820.46 & 2960.79 & 5730.39 & 4436.20 & 6349.22 & 3472.94 & 4245.02 \\
\hline Highest & 5575.03 & 5575.03 & 5575.03 & 5575.03 & 5575.03 & 5575.03 & 5575.03 & 5575.03 \\
\hline Lowest & 2945.17 & 2586.90 & 2393.94 & 5066.58 & 2864.25 & 5086.83 & 2215.48 & 3802.72 \\
\hline Mean & 3822.16 & 3923.33 & 3264.34 & 5881.55 & 4097.97 & 6355.33 & 3500.64 & 4406.47 \\
\hline${ }^{\wedge} \mathrm{MSG}$ & $369720.80^{\mathrm{ns}}$ & $1635735.75^{* *}$ & $732799.11^{*}$ & $441513.96^{\mathrm{ns}}$ & $1377557.04 * *$ & $1000938.21 * *$ & $1552148.92 * *$ & \\
\hline MSE & 471131.13 & 322858.63 & 437555.93 & 480928.05 & 450419.00 & 352017.51 & 296528.90 & \\
\hline CV $(\%)$ & 17.96 & 14.48 & 20.26 & 11.79 & 16.38 & 9.34 & 15.56 & \\
\hline
\end{tabular}

$\mathrm{ns}=$ not significant; $*$ and $* *$ significant at 6.4 and $1 \%$, respectively, by the $\mathrm{F}$-test; ${ }^{\wedge} \mathrm{MSG}, \mathrm{MSE}$ and $\mathrm{CV}=$ mean square of genotypes, error and coefficient of variation, respectively.

Table 3. Summary of combined variance analysis for grain yield and analysis of the deployment of the $\mathrm{G} \times \mathrm{E}$ interaction by the AMMI method.

\begin{tabular}{lrr}
\hline Source of variation & d.f. & MS \\
\hline Blocks (environment) & 14 & 2920365.03 \\
Genotype (G) & 24 & $1766757.31^{* *}$ \\
Environment (E) & 6 & $109611882.64^{* *}$ \\
G x E & 144 & $890609.41^{* *}$ \\
IPCA1 & 29 & $2109573.04^{* *}$ \\
Residue (IPCA1) & 115 & $583218.58^{* *}$ \\
IPCA2 & 27 & $868070.90^{* *}$ \\
Residue (IPCA2) & 88 & $495820.71^{\mathrm{ns}}$ \\
Error & 336 & 401634.16 \\
CV $(\%)$ & & 14.38
\end{tabular}

d.f. $=$ degrees of freedom; $\mathrm{MS}=$ mean squares; $\mathrm{CV}=$ coefficient of variation; $\mathrm{ns}=$ not significant. ${ }^{* *}$ Significant at $1 \%$ by the F-test. 
Genotypes 0307063,0307047 , and 0307341 stood out as the lowest contributors to the G x E interaction, under the Wricke and AVS methods. These genotypes also showed the greatest fit to the regression model and regression coefficients statistically equal to 1. Among these hybrids, the only important result for the production of grains in these hybrids was evident in genotype 0307047 in Rio Verde (Table 4).

\begin{tabular}{|c|c|c|c|c|c|c|c|}
\hline \multirow[t]{2}{*}{ Hybrid } & \multicolumn{3}{|c|}{ Lin and Binns $\left(x 10^{-5}\right)$} & \multirow[t]{2}{*}{$\omega(\%)^{1}$} & \multirow[t]{2}{*}{$\beta$} & \multirow[t]{2}{*}{$\mathrm{R}^{2}(\%)$} & \multirow[t]{2}{*}{ ASV } \\
\hline & P & $\mathrm{P}_{\mathrm{G}}$ & $P_{G \times E}$ & & & & \\
\hline 0009061 & 3.26 & 2.64 & 0.63 & 1.67 & $0.82^{\text {ns }}$ & 93.21 & 28.01 \\
\hline 0144013 & 6.15 & 4.63 & 1.52 & 3.23 & $0.729 *$ & 86.36 & 18.61 \\
\hline 0307001 & 6.96 & 5.67 & 1.29 & 3.63 & $1.055^{\mathrm{ns}}$ & 86.48 & 16.90 \\
\hline 0307047 & 4.99 & 3.85 & 1.15 & 1.01 & $0.991^{\text {ns }}$ & 95.23 & 7.72 \\
\hline 0307061 & 4.60 & 3.48 & 1.11 & 3.68 & $0.737 *$ & 83.13 & 45.43 \\
\hline 0307063 & 5.37 & 4.83 & 0.54 & 0.73 & $1.041^{\mathrm{ns}}$ & 96.97 & 5.99 \\
\hline 0307071 & 6.49 & 4.17 & 2.32 & 4.80 & $1.26^{*}$ & 90.53 & 37.67 \\
\hline 0307087 & 5.61 & 3.81 & 1.80 & 2.54 & $1.13^{\text {ns }}$ & 92.28 & 27.24 \\
\hline 0307091 & 16.99 & 11.75 & 5.24 & 9.34 & $0.847^{\mathrm{ns}}$ & 62.43 & 43.49 \\
\hline 0307095 & 14.52 & 12.48 & 2.04 & 3.11 & $1.088^{\mathrm{ns}}$ & 89.18 & 12.08 \\
\hline 0307131 & 13.17 & 9.21 & 3.96 & 10.05 & $1.554 * *$ & 92.98 & 77.11 \\
\hline 0307341 & 6.01 & 5.41 & 0.60 & 1.03 & $1.12^{\text {ns }}$ & 97.22 & 6.36 \\
\hline 0307343 & 5.56 & 4.14 & 1.42 & 3.22 & $0.923^{\text {ns }}$ & 84.95 & 28.22 \\
\hline 0307401 & 12.68 & 10.30 & 2.38 & 4.83 & $1.225^{\mathrm{ns}}$ & 89.05 & 28.64 \\
\hline 0307421 & 5.20 & 4.28 & 0.92 & 5.99 & $0.701 *$ & 70.83 & 53.75 \\
\hline 0307509 & 16.40 & 14.08 & 2.32 & 3.89 & $1.239^{\mathrm{ns}}$ & 92.05 & 45.91 \\
\hline 0307511 & 12.39 & 9.78 & 2.61 & 4.16 & $1.293^{*}$ & 93.46 & 45.85 \\
\hline 0307541 & 6.17 & 5.31 & 0.86 & 2.65 & $0.997^{\text {ns }}$ & 88.50 & 25.65 \\
\hline 0307561 & 4.79 & 4.13 & 0.65 & 1.50 & $0.92^{\text {ns }}$ & 92.67 & 23.05 \\
\hline 0307651 & 8.07 & 6.82 & 1.25 & 3.06 & $1.319^{* *}$ & 97.34 & 38.36 \\
\hline 0307671 & 6.85 & 5.74 & 1.11 & 2.68 & $0.891^{\text {ns }}$ & 86.98 & 5.31 \\
\hline 0307689 & 7.88 & 6.46 & 1.42 & 4.20 & $1.001^{\mathrm{ns}}$ & 83.04 & 16.92 \\
\hline $1 \mathrm{G} 282$ & 2.15 & 1.33 & 0.82 & 5.43 & $0.726^{*}$ & 73.53 & 47.69 \\
\hline BRS 308 & 6.67 & 2.48 & 4.19 & 11.65 & $0.324 * *$ & 48.57 & 75.21 \\
\hline BRS 330 & 7.76 & 7.64 & 0.12 & 1.94 & $1.068^{\mathrm{ns}}$ & 92.70 & 13.44 \\
\hline
\end{tabular}

Pre-commercial hybrid 0009061 stood out as the highest mean for grain production among all pre-commercial hybrids. Considering all environments, this hybrid also showed the least contribution to the G x E interaction based on the Wricke (1965) method, a low value of the Lin and Binns (1988) index, and showed a good fit to the regression model with a regression coefficient statistically equal to 1 .

Cultivar BRS 308 presented elevated means for grain production; however, it showed generally uninteresting results for stability and adaptability under all models, because the variation of its means was quite inconsistent with variation in environmental means.

The Eberhart and Russell (1966) method indicated that the cultivar BRS 308 shows adaptability to unfavorable environments, although the fit to the model was low. No other method was able to identify groups of environments that indicated specific adaptability for this cultivar.

Cultivar 1G282 was one of the best producing hybrids, and this genotype also presented the best result for the Lin and Binns (1988) index, which indicated good overall performance. However, this hybrid also showed a high contribution to the interaction, indicating specific adaptability. 
Using the AMMI method, environments were grouped to indicate the genotypes that showed specific adaptability to each environment. For the deployment of the $\mathrm{G} x \mathrm{E}$ interaction, according to the AMMI model, the first 2 principal components were used. In consequence, this model explained $65.98 \%$ of the variance (sum of squares) due to the $\mathrm{G} \times \mathrm{E}$ interaction; $47.70 \%$ was explained by AMMI1 (Table 3 ).

In the biplot analysis (Figure 1), the cultivar 1G282 and hybrids 0307061 and 0307421 were located near the environments of Guaíra, Sete Lagoas, and Vilhena. These 3 genotypes showed means well above each of these environments. Cultivar 1G282 stood out as the most productive in Sete Lagoas and was the 2nd most productive genotype in Guaíra and in Vilhena.

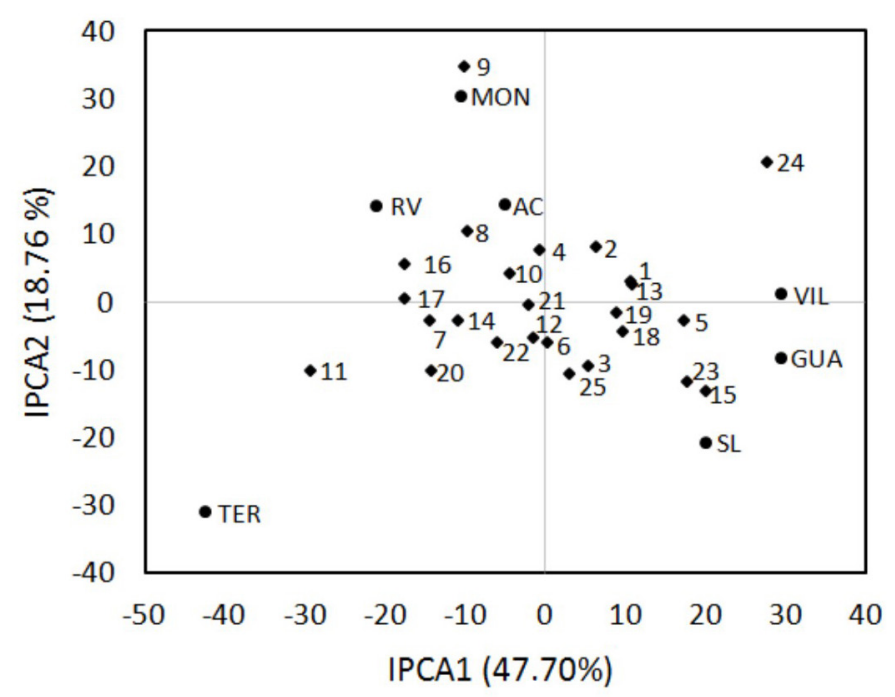

Figure 1. Biplot AMMI2 for productivity of grains with 25 grain sorghum hybrids in seven environments. The codifications of hybrids and environments are according to Table 2 ; hybrids are shown in ascending order.

Hybrids 0307087 and 0307091 showed the shortest distance from the environments Água Comprida, Montividiu, and Rio Verde in the biplot analysis. Hybrid 0307087 showed the 1st and 3rd highest means in Rio Verde and Montividiu, respectively, and hybrid 0307091 had the 7th and 2nd highest means, respectively, in these environments.

In Água Comprida, only hybrid 0307091 presented a mean above the overall mean, but it was not very productive.

According to the biplot analysis, hybrids 0307131 and 0307651 were located near Teresina and were also the 2 most productive genotypes in this location, indicating specific adaptability in this environment.

\section{DISCUSSION} materials.

The significant interaction justify the need to identify the most stable and productive

Results of 0307063, 0307047, 0307341, and 0009061 suggested that variation among 
the means of these hybrids coincided with variation of environmental means, indicating that these hybrids were stable and show overall adaptability. However, just 0009061 reported high grain production among all environments.

The AMMI method and the grain productions indicated the potential for new evaluations of 0307087 and 0307091 in the southeast region of the State of Goiás.

The association between the AMMI and the Eberhart and Russell (1966) methods was very useful in explaining the performance of hybrids with adaptability to favorable environments. Hybrids 0307071, 0307131, 0307511, and 0307651 showed regression coefficients that were statistically higher than 1 and were a great fit to the model. Furthermore, the biplot analysis showed that these hybrids were located at a distance relatively close to the environments Teresina and Rio Verde, which were the only sites showing a positive environmental index.

Such identification of environments with similar response patterns and genotypes with specific adaptabilities to these environments is an important advantage of the AMMI method compared to the other methods commonly employed (Silva Filho et al., 2008).

The Lin and Binns (1988) method was the only method to dispense with the analysis of means for selection, since it presented high correlations with the means (Table 5). This observation is common in the literature (Cargnelutti Filho et al., 2007; Silva Filho et al., 2008; Scapim et al., 2010).

Table 5. Spearman's correlation coefficient between stability and adaptability statistics and the mean.
\begin{tabular}{lccccc}
\hline & ASV & $\omega$ & $\beta$ & $\mathrm{R}^{2}$ & $\mathrm{P}$ \\
\hline Mean & $0.08^{\text {ns }}$ & $-0.16^{\text {ns }}$ & $-0.61^{\text {** }}$ & $-0.19^{\text {ns }}$ & $-0.90^{* *}$ \\
ASV & & $0.78^{* *}$ & $-0.04^{4 s}$ & $-0.35^{\text {ns }}$ & $0.11^{\text {ns }}$ \\
$\omega$ & & $-0.09^{\text {ns }}$ & $-0.66^{* *}$ & $0.40^{*}$ \\
$\beta$ & & & $0.66^{* *}$ & $0.57^{* *}$ \\
$\mathrm{R}^{2}$ & & & & $0.01^{\text {ns }}$ \\
\hline
\end{tabular}

ASV $=$ AMMI stability value; $\mathrm{ns}=$ not significant. $* \mathrm{P} \leq 0.05 . * * \mathrm{P} \leq 0.01$.

In general, more productive individuals and individuals with better performance indices $(\mathrm{P})$ showed a tendency toward adaptability in unfavorable environments $(\beta<1)$, which is an uncommon result (Farias et al., 1997; Cargnelutti Filho et al., 2007; Silva Filho et al., 2008; Scapim et al., 2010). One explanation for this observation may be that since sorghum is an off-season culture, its breeding has been selected specifically for unfavorable environments.

The Wricke (1965) and Purchase et al. (2000) methods, which are based on the contribution to the interaction, were in overall agreement, as their results were highly correlated. Mohammadi and Amri (2008) also demonstrated high correlations between these 2 methods, and Silva and Duarte (2006) observed high correlations between the ranks of the Wricke (1965) and the IPCA1 methods.

The statistic $\mathrm{R}^{2}$, which indicates stability by the regression model, agrees with results of methods based on decomposition of the interaction, in which the genotype indicates overall adaptability $(\beta=1)$. If the genotype indicates adaptability to favorable or unfavorable environments, it can be determined as stable based on the Eberhart and Russell (1966) method, even if it shows a high contribution to the interaction. This explains why the correlation of $\mathrm{R}^{2}$ with ASV and $\omega$ was not so pronounced. Thus, $\mathrm{R}^{2}$ can be considered as complementary to ASV and $\omega$.

With respect to indications for specific adaptability, the results of the Lin and Binns (1988) method appeared to contradict with those of the other methods, as some individuals with indications of specific adaptability by the other methods were classified as either having 
overall adaptability (e.g., cultivar 1G282), or non-adapted. Therefore, we can identify the hybrids that suggest adaptability to favorable environments and southeast Goiás.

\section{ACKNOWLEDGMENTS}

Research supported by Fundação de Amparo à Pesquisa do Estado de Minas Gerais (FAPEMIG). Fundação de Amparo à Pesquisa do Estado do Rio de Janeiro (FAPERJ) and Coordenação de Aperfeiçoamento de Pessoal de Nível Superior (CAPES) granted the Master's fellowship.

\section{REFERENCES}

Cargnelutti Filho A, Perecin D, Malheiros EB and Guadagnin JP (2007). Comparação de métodos de adaptabilidade e estabilidade relacionados à produtividade de grãos de cultivares de milho. Bragantia 66: 571-578.

Cruz CD and Regazzi AJ (1997). Modelos Biométricos Aplicados ao Melhoramento Genético. Editora UFV, Viçosa.

Eberhart SA and Russell WA (1996). Stability parameters for comparing varieties. Crop Sci. 6: 36-40.

Farias FJC, Ramalho MAP, Carvalho LP, Moreira JAN, et al. (1997). Parâmetros de estabilidade proposto por Lin e Bins 1998, comparados com o método da regressão. Pesq. Agropec. Bras. 32: 407-414.

Lin CS and Binns MR (1988). A superiority measure of cultivar performance for cultivar x location data. Can. J. Plant Sci. 68: 193-198.

Mariotti JA, Oyarzabal ES, Osa JM, Bulacio ANR, et al. (1976). Análisis de estabilidad y adaptabilidad de genótipos de caña de azucar. I. Interacciones dentro de una localidad experimental. Ver. Agronóm. del Noroeste Argentino, Tucuman 13: 105-127.

Mekbib F (2003). Yield stability in common bean (Phaseolus vulgaris L.) genotypes. Euphytica 130: 147-153.

Mohammadi R and Amri A (2008). Comparison of parametric and non-parametric methods for selecting stable and adapted durum wheat genotypes in variable environments. Euphytica 159: 419-432.

Pena GF, do Amaral ATJ, Goncalves LS, Candido LS, et al. (2012). Stability and adaptability of popcorn genotypes in the State of Rio de Janeiro, Brazil. Genet. Mol. Res. 11: 3042-3050.

Pimentel-Gomes F (2009). Curso de Estatística Experimental. Editora FEALQ, Piracicaba.

Purchase JL, Hatting H and Van Deventer CS (2000). Genotype x environment interaction of winter wheat in south Africa: II. Stability analysis of yield performance. S. Afri. J. Plant Soil 17: 101-107.

Scapim CA, Pacheco CAP, Amaral Júnior AT, Vieira RA, et al. (2010). Correlations between the stability and adaptability statistics of popcorn cultivars. Euphytica 174: 209-218.

Silva WCJ and Duarte JB (2006). Métodos estatísticos para estudo de adaptabilidade e estabilidade fenotípica em soja. Pesq. Agropec. Bras. 41: 23-30.

Silva Filho JL, Morello CL, Farias FJC, Lamas FM, et al. (2008). Comparação de métodos para avaliar a adaptabilidade e estabilidade produtiva em algodoeiro. Pesq. Agropec. Bras. 43: 349-355.

Steel RGD and Torrie JH (1960). Principles and Procedures of Statistics. McGraw-Hill, New York.

Vilela FO, Amaral Júnior AT, Gonçalves LSA, Barbé TC, et al. (2011). Stability of F7:8 snap bean progenies in the Northern and Northwestern regions of Rio de Janeiro State. Hort. Bras. 29: 84-90.

Wricke G (1965). Zur Berechnung der Ökovalenz bei Sommerweizen und Hafer. Zeitschrift für Pflanzenzüchtung 52: $127-138$.

Zobel RW, Wright MJ and Gauch Júnior HG (1988). Statistical analysis of a yield trial. Agr. J. 80: 388-393. 